\title{
Trust as Accelerator of Informal Institutions (The case of Georgian Economy)
}

\author{
Tsotne Zhghenti
}

Speaking about quality of formal or informal institutions one of the most important determinant is trust. How trustworthy are institutions? Are they able to lower uncertainty and to reduce transaction costs for society?

Trust is a huge problem in post-transition world. Where in planned economy formally the only formal trustworthy institutions were centralized state organizations (even they hadn't enough trust). Lack of private contracts moves trust distribution to strange ways.

Development and evolution of trust can by determined by Trust Stack (Rachel Botsman, 2017) trust to idea, platform and individual. Trust in individuals is the final step of establishing trustworthy formal or informal arrangements. Level of personal trust can tell much about interactions of working informal norms.

To analyze general trust levels in post-transition countries we use data from - World Values Survey (2010-2014). We will compare personal trust levels and informal institutions level across these countries. Data about informal institutions based on global competitiveness indices.

Keywords: Institutions, Trust, Informal Institutions, Post-transition Economy. 